\title{
Saskatchewan First Nations drafts suicide prevention plan
}

- Cite as: CMAJ 2017 October 16;189:E1295-6. doi: 10.1503/cmaj.109-5502

Posted on cmajnews.com on September 25, 2017.

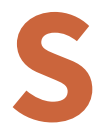
askatchewan First Nations are drafting a suicide prevention strategy to stem the rising rate of death among their youth.

"This is a priority for our leadership to address the suicide crisis that has been ongoing," says Heather Bear, vice-chief of the Federation of Sovereign Indigenous Nations. "Children as young as 10 years old are committing suicide. Enough is enough. We can't wait for the government to come up with a strategy."

Bear is alarmed by what the federation's initial investigation has already shown about suicide rates in Saskatchewan. First Nations' girls age 10-19 are taking their lives at a rate 26 times higher than non-Indigenous girls in the same age range, according to University of Saskatchewan researcher Jack Hicks, who analyzed data from the province's chief coroner.

Last year alone, 11 First Nations' girls and two boys aged 10-19 took their lives. The suicide rate is six times higher for First Nations' boys than their provincial peers, according to Hicks' analysis.

For Bear, this issue goes beyond statistics. In 2004, her 19-year-old daughter took her life. "Our families are going through grief and loss, and it's continual. The post-traumatic stress, the trauma - it's been ongoing."

Overall, First Nations' people are dying by suicide at a rate 4.3 four times higher than non-First Nations' people in Saskatchewan. Since 2005, close to 500 First Nations' people have taken their lives in Saskatchewan, according to Hicks, an adjunct professor of community health and epidemiology and the federation's technical advisor.

In May, Saskatchewan's health minister tabled data in the legislature citing 265 suicides by First Nations' people. That figure is $40 \%$ lower than the coroner's records indicate. The discrepancy may be due to the definition of "First Nations" used by the ministry, which includes only those registered as having Indian status. The coroner's data, by contrast, uses the category "North American Indian," which also includes non-status First Nations' people.

By May 2018, after circulating a discussion paper and holding consultations throughout Saskatchewan's 72 First
Nations' communities, the federation plans to release what Bear is calling a multifaceted suicide prevention strategy.

"We're taking very calculated, evidence-based steps ... and we want a plan that's going to work for our people, by our people," Bear says.

The resulting document will incorporate community-based solutions, including those suggested by youth. It will also be informed by the World Health Organization's recommendations, and by Quebec's suicide prevention strategy, which reduced the province's overall youth suicide rates by half in just over a decade.

Implementing the strategy will require coordination and financial resources from both the federal and the

\section{Saskatchewan Suicide Rate, 2005-16, by Ethnicity and Sex}

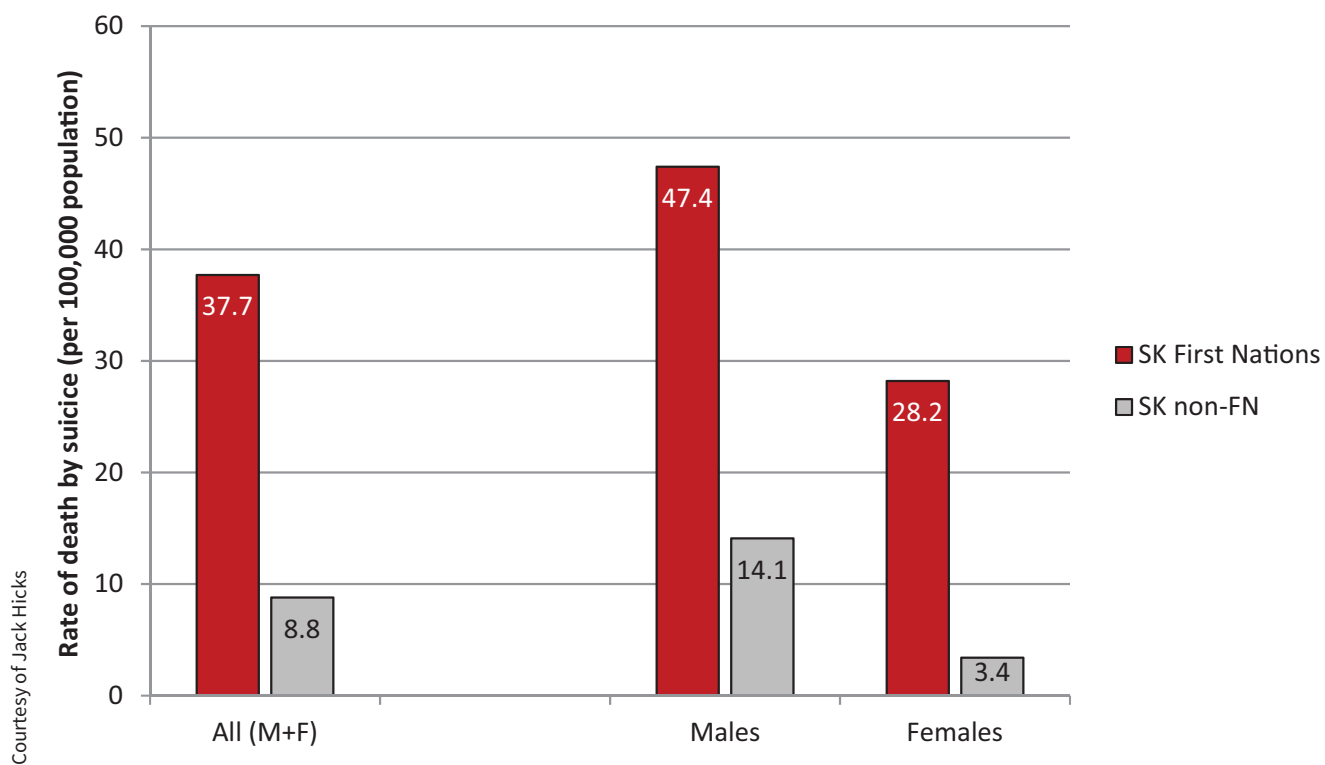

Suicide rates among First Nations' people far exceed that of other Saskatchewan residents. $F=$ female, $F N=$ First Nations, $\mathrm{M}=$ male, $\mathrm{SK}=$ Saskatchewan. 
provincial government, said Bear. Improving the lives of First Nations' youth will require addressing the social determinants of health and the economic disparities they face. It is also critical to get to the root causes of suicide, including the sexual abuse of children, "in a meaningful way, which is going to take meaningful resources," said Bear.

Bear's vision is to end the suicide crisis, so future generations won't have to experience such crippling losses. She hopes the strategy will bring some hope to the communities, particularly those in Northern
Saskatchewan, that have been devastated by suicide. "Our people are the poorest of the poor. What hope do we give our people when we look at a strategy and those kinds of things are not addressed?"

Laura Eggertson, Ottawa, Ont. 